\title{
Emerging arboviruses in the urbanized Amazon rainforest
}

\author{
Degradation of rainforest, extreme weather events, and climate change affect the spread of \\ mosquito borne diseases like dengue, chikungunya, and Zika, write Rachel Lowe and colleagues.
} Urgent action is needed

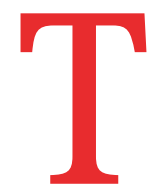

he rapidly changing fate of the Amazon, an ecosystem we all depend on, has been highlighted by rampant wildfires, extreme droughts, and deforestation in recent years. For indigenous communities, land is sacred and typically is used for sustainable subsistence. But these communities are increasingly threatened by illegal mining, livestock, and monoculture practices.

Brazilian satellite images show $64 \%$ more deforestation in 2020 than in 2019. This promotes conflict and environmental degradation, exacerbates health risks for indigenous populations, and leads to loss of ecosystem at local, regional, and global scales.

The Amazon region is at a critical moment of history. Action to protect the health and wellbeing of traditional communities, promote sustainable development, and protect forest habitat will not come from governments. How can the medical, public health, environmental, and policy communities engage effectively to tackle such a complex challenge?

We consider this question with a focus on arboviruses, including dengue, chikungunya, and Zika. The emergence and expansion of these arboviral diseases

\section{KEY RECOMMENDATIONS}

- Integrated surveillance methods for endemic and emerging infectious agents are needed across all countries in the Amazon region

- Action is needed to monitor deforestation in coordination with health surveillance and to build resilience to extreme weather events

- Climate forecasts should be used to predict and prepare for disease outbreaks

- Disease control and prevention strategies should include better representation of women and traditional communities is an important global threat. They are transmitted to humans by females of two resilient mosquitoes, Aedes aegypti and Aedes albopictus. These vectors' geographical ranges have been expanding latitudinally and into the Amazon region, enabled by climate change and their adaptation to humans' domestic environment.

Environmental and climatic changes affect transmission of other vectorborne diseases, but arboviruses show these effects in the context of rapid urbanization. Malaria, another endemic disease in the Amazon, has been discussed extensively elsewhere, including recommendations for action. ${ }^{1}$ It is primarily a rural and periurban disease and its mosquito vectors do not rely on the built environment and water stored by humans. Nevertheless, our recommendations related to arboviruses extend to vectorborne pathogens more generally. Although we focus on Brazil, the country containing the largest proportion of the Amazon ecosystem, disease transmission does not recognize national borders and cooperative regional efforts are required. ${ }^{1}$

\section{Arboviruses edging into the rainforest}

Dengue is a climate sensitive disease that has substantially expanded its global range in the past 50 years. It now accounts for an estimated 10000 deaths and 100 million symptomatic infections a year in over 125 countries. ${ }^{2}$ Since 2005 , chikungunya and Zika viruses have also begun to extend their reach beyond Africa and Asia. ${ }^{3}$ Chikungunya emerged in the western hemisphere in 2013 , leading to more than a million cases in the Americas within a year. ${ }^{4}$

Zika reached the Americas by 2014, and the discovery of links between Zika virus infection and a neurological complication in newborn babies, which later became known as congenital Zika syndrome, led the World Health Organization to declare a public health emergency of international concern in $2016 .^{5}$
These arboviruses continue to affect the Americas, and in 2019 the region reported more than three million dengue cases, the largest recorded epidemic to date. ${ }^{6}$ Dengue re-emerged in Brazil in the 1980s, with marked expansion in transmission in recent years. Spread into previously isolated Amazon regions (fig 1$)^{9}$ is associated with Ae aegypti re-establishing itself after a successful elimination campaign during the 1940 s and 1950s.

Larger cities were the first to be affected, including Iquitos in Peru ${ }^{10}$ and Belém and Manaus in Brazil. ${ }^{11}$ In 2016, 90 Amazonian municipalities had reported presence of $A e$ aegypti, with 24 reporting high abundance. Importantly, Ae aegypti dwell in water holding containers, which are abundant in urban landscapes. ${ }^{11} 12$ Dengue vectors have been expanding from urban centers to neighboring rural areas and into the urbanized forest (areas with increased presence of non-indigenous settlements but with gradients more complex than simple city versus rural classifications ${ }^{1314}$ ). In the Peruvian Amazon, for example, proximity to Iquitos has been shown to increase the odds of Aedes's establishment. ${ }^{10}$

The establishment of Aedes mosquitoes in the Brazilian Amazon has been accompanied by large outbreaks of arboviral diseases. Mean annual dengue cases doubled between 1998-2008 (27 900/ year) and 2009-18 (52 363/year), with epidemics in 2001 (51000 cases), when the type 3 virus first appeared in the country, and in 2010 and 2011 (98000 and 119000 cases), when the type 4 virus first appeared. ${ }^{15}$

The first municipalities to experience dengue outbreaks were urban centers, including Manaus and Boa Vista, with high population density but lower access to basic services such as piped water than in other parts of Brazil (figs 2 and 3). Large areas of the western Amazon have not yet seen dengue outbreaks, although the area of permanent dengue transmission is expanding west, and over the past 20 years 

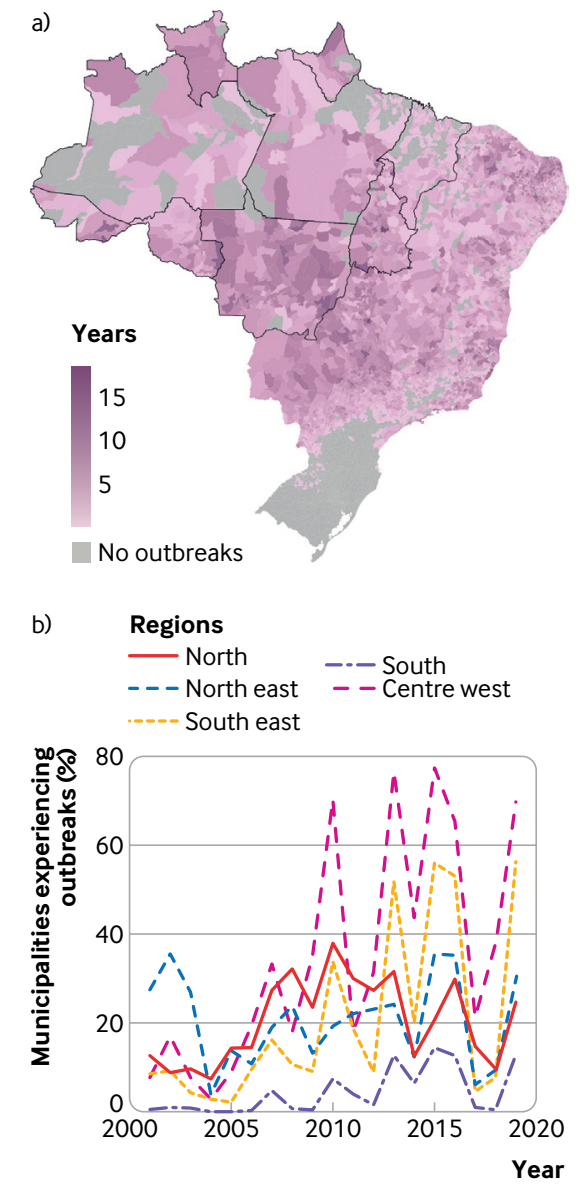

Fig 1 | Expansion of dengue transmission in Brazil during the 21st century. Top: Number of years each municipality experienced an outbreak between 2001 and 2019 (defined by the Brazilian Ministry of Health as $\geq 300$ cases per 100000 inhabitants). ${ }^{7}$ The nine Brazilian states encompassing most of the Amazon forest biome with a population of about 27 million are outlined in bold ${ }^{8}$ Bottom: Percentage of municipalities in each region experiencing an outbreak by year. The north region mostly comprises the Amazon rainforest.

increasing numbers of cities in the North region have had outbreaks (fig 1).

Chikungunya and Zika first appeared in Brazil in 2013 and 2014. Brazilian Ministry of Health data show a Zika epidemic occurred in 2016 (10311 cases) and a chikungunya epidemic in 2017 (13 335 cases). Both viruses persist in the region, with new cases reported every year. Other arboviruses, including Mayaro, Oropouche, and yellow fever viruses have also been associated with epidemics in humans and pose a public health threat. ${ }^{17}$

\section{New opportunities for mosquitoes to thrive}

The Brazilian Amazon is one of the world's richest reservoirs of arboviruses, ${ }^{18}$ with more than 180 identified. They are maintained within a sylvatic cycle in the forest, in which several insect species act as vectors and wild vertebrates are hosts. Forest disturbances (for example, deforestation, mining, and infrastructure projects such as highways and dams) create conditions that bring humans close to those areas, increasing the likelihood of new zoonosis ${ }^{1920}$ and resurgences of others. For example, illegal gold mining in the rainforest attracts nonimmune workers into settler communities with inadequate healthcare, which has led to hotspots of malaria resurgence in Venezuela. $^{2122}$

Development projects in the Brazilian Amazon have spawned settlements without basic infrastructure such as access to piped water and waste collection. This can create ideal conditions for Ae aegypti to lay eggs. ${ }^{1}$ Land use and land cover changes combined with unplanned, precarious urbanization and increased human mobility can allow invasive vector species and novel pathogens to travel greater distances. In Acre, Brazil, road construction and increasing connectivity between urban and rural areas correlate with emergence of dengue. ${ }^{23}$

Deforestation and associated human settlement are taking place against a backdrop of rapid shifts in the climate. The Brazilian Amazon region has experienced an increasing number of severe extreme weather events such as flooding, drought, and fires over the past two decades. ${ }^{24}$ These hydrometeorological extremes are closely tied to intense El Niño and La Niña events ${ }^{25}$ that affect precipitation and temperature in the Amazon basin.

El Niño leads to warmer, drier weather in the Amazon basin whereas La Niña brings wetter, cooler periods (fig 4). ${ }^{2627}$ There is some uncertainty, with studies indicating both a strengthening and a weakening of extreme El Niño in the future. ${ }^{2829}$ However, the Amazon rainforest experienced record breaking warming and extreme drought during the strong 2015-16 El Niño event. ${ }^{30}$ Increased drought can lead to more frequent fires, generating further deforestation. Loss of trees alters the Amazon's hydrological cycle, influencing regional and global climate. ${ }^{31}$

Climate change projections show that by $2060-80$ the Amazon is likely to warm $1-2^{\circ} \mathrm{C}$ above the global average increase in surface temperature because of periods of intense drought and reduced cloud cover, which increase net surface shortwave radiation. ${ }^{8}$ This scenario points toward surpassing a tipping point to a degraded savanna-like ecosystem and increased droughts, which in turn will harm the global climate system. ${ }^{3233}$

Temperature and precipitation are important drivers of seasonality and interannual variability in arbovirus transmission. As shown for dengue, the relation between anomalous climatic events and transmission is complex, non-linear, and often delayed by several months. ${ }^{34}$ Ambient temperature affects mosquito reproduction, survival, and biting rates, with warmer temperatures increasing risk of transmission up to a maximum of $34^{\circ} \mathrm{C} .{ }^{35}$ Warm temperatures also affect the size and duration of arboviral disease outbreaks, with annual average temperatures $25-35^{\circ} \mathrm{C}$ producing the largest epidemics in areas with low seasonal temperature variation, such as the Amazon. ${ }^{36}$
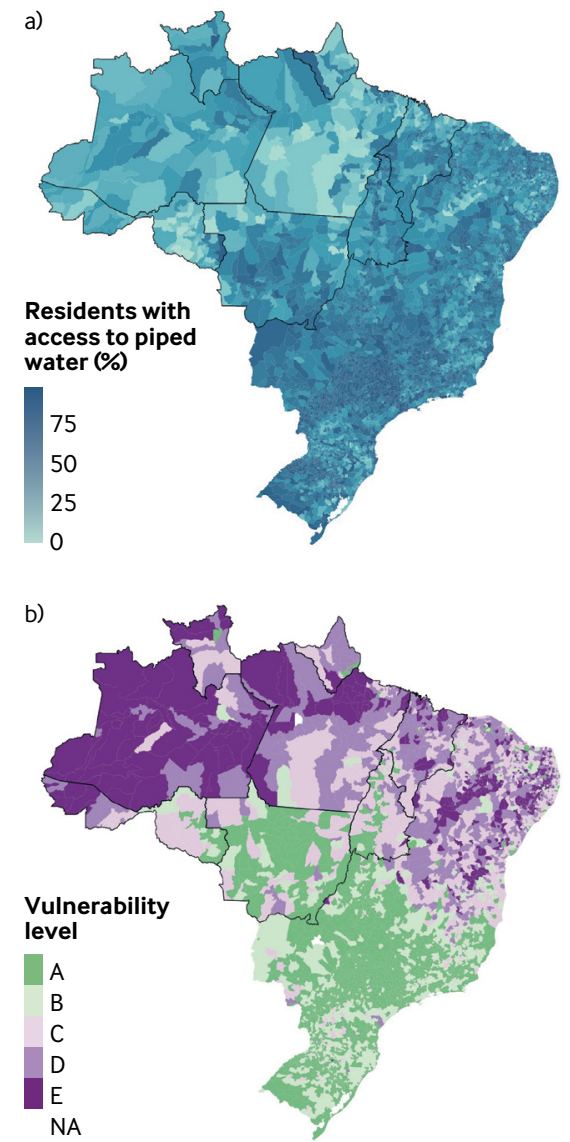

Fig 2 | Top: Proportion of Brazilian residents with access to piped water network (2010 population census, Brazilian Institute for Geography and Statistics)(IBGE). Bottom: Socioeconomic vulnerability index. ${ }^{16}$ The index ranges from $A$ (least vulnerable) to $E$ (most vulnerable). The nine Brazilian states encompassing most of the Amazon forest biome are outlined in bold 

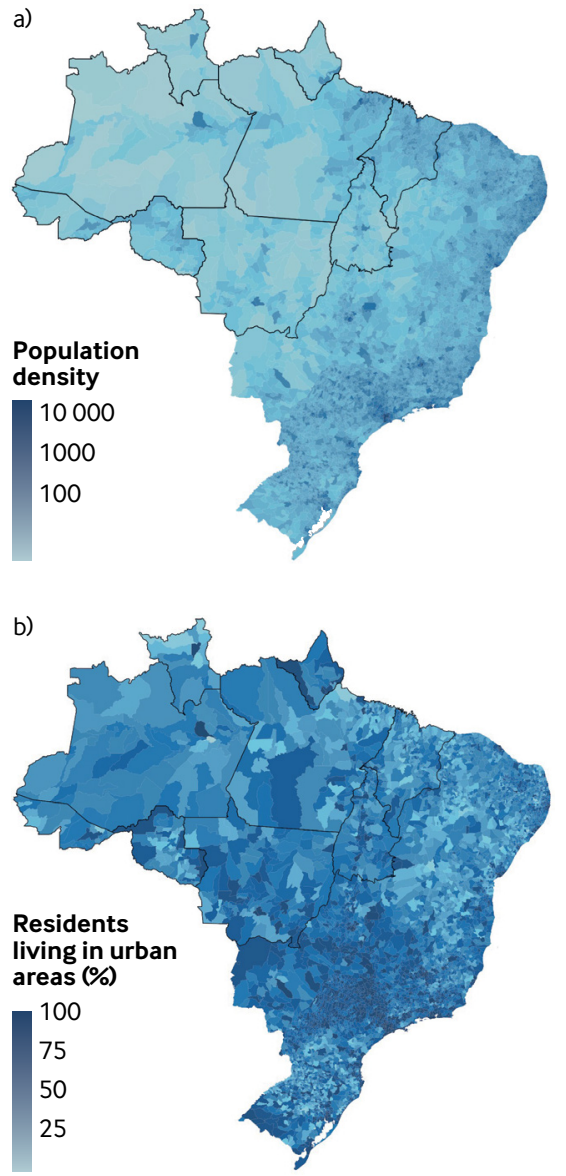

Fig 3 | Population density (per square $\mathrm{km}$ ) of Brazil. Bottom: Proportion of residents living in urban areas (2010 population census, Brazilian Institute for Geography and Statistics).

Although rainfall is conducive to outbreaks of mosquito-borne disease through an increase in mosquito breeding sites, El Niño induced warm and dry conditions have also been associated with an increased risk of dengue fever in parts of the Americas. ${ }^{3437}$ Periods of drought may lead to water supply shortage, encouraging household improvised water storage, which can create additional vector habitats and increase contact between mosquitoes and humans. Despite its immense water resources, the Amazon basin has serious water disruption and sewage problems, ${ }^{38}$ with an unacceptably low proportion of the population having access to the piped water network (fig 2). This region is also the most vulnerable in Brazil in terms of infrastructure and access to electricity and running water.

An increase in extreme weather events related to a changing climate is therefore likely to raise the risk of outbreaks of existing arbovirus diseases and the emergence of new ones. The climate effects will occur and act synergistically with the ongoing trend in urbanization of the rainforest. The variability, complexity, and uncertainty of the health responses argue for a precautionary approach based on surveillance, preparedness, and alert systems. These measures should accompany broader efforts to reduce changes to the environment itself, on deforestation, climate change, and a sustainable path for the region.

\section{Holistic intersectorial surveillance systems}

New surveillance methods for endemic and emerging infectious agents and management of people with fever are a priority. ${ }^{31}$ In line with the Global Vector Control Response recommendations, ${ }^{33}$ pathogen, vector, and epidemiological surveillance systems should be integrated with environmental and climate information systems. A One Health approach at the human-animal ecosystem interface is needed for effective investigation, prevention, and control of potential spillover and spread of emerging vectorborne zoonotic diseases.

The public health community should work with the environmental sector to monitor deforestation and biodiversity and to identify hotspots for sampling and active integrated surveillance. Pathogens, vectors, wildlife, and human hosts do not recognize geopolitical boundaries in the rainforest, which makes cross-border and regional alliances imperative. Thus, integrated surveillance system protocols should be compatible between all relevant countries. $^{1}$

The covid-19 crisis has further exposed the vulnerability of the Amazon region to the effects of a large epidemic. Disease surveillance and control in this forest is a formidable task because of its size, limited communication infrastructure, cost of transportation, and lack of specific disease control protocols for diverse ethnic groups with different levels of vulnerability. Surveillance systems used in other areas (such as Infodengue ${ }^{39}$ ) could be adapted for the Amazon, with the inclusion of participatory surveillance efforts by indigenous groups (https://cimi. org.br/coronavirus/) and non-governmental organizations to improve outbreak detection in small communities (https:// covid19.socioambiental.org/). These alerts can be easily integrated with a response protocol, improving the precision and speed of control actions.

Given the sensitivity of the Amazon rainforest to El Niño and La Niña events, outbreak prediction based on seasonal climate forecasts can give more time to prepare public health systems for heightened risk of disease outbreaks associated with extreme weather events. ${ }^{340}$ Early interventions may include purchasing of diagnostic equipment and mosquito control supplies (such as insecticide and larvicide) and environmental hygiene, including maintenance of water storage containers.

Mosquito breeding habitats should be destroyed not only during the warm and rainy season but also during and after droughts. ${ }^{34}$ Combining seasonal climate
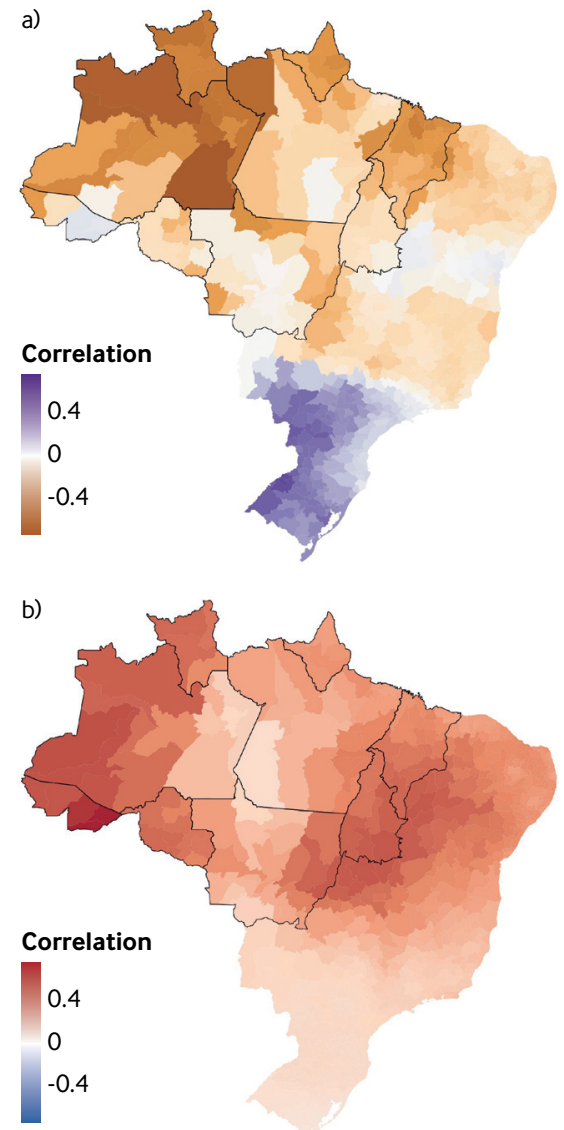

Fig 4 | Correlation between the Nino3.4 index (Nov-Jan) and the Palmer drought severity index (Feb-Apr) (top) and minimum temperature between 2001 and 2017 (bottom). The nine Brazilian states encompassing most of the Amazon forest biome are outlined in bold. The Niño 3.4 index is a measure of the sea surface temperature anomalies in the Niño 3.4 region of the Pacific Ocean. The Niño 3.4 index is negatively correlated with the Palmer drought severity index in the Amazon region, a measure of meteorological drought ranging from -10 (extremely dry) to +10 (extremely wet), and positively correlated with minimum temperature 
forecasts and Earth observations with local seroprevalence surveys could improve the detection of emerging diseases associated with anomalous climate events. ${ }^{41}$ Use of existing networks of malaria diagnostic and treatment units has also been proposed to detect acute Chagas disease across the Amazon. ${ }^{42}$

For early warnings to translate to early action, health services must dedicate staff to educate and mobilize local communities, including schools, community organizations, and churches. Community engagement and educational programs on recognizing risk factors, symptoms, and vectors should become a key component of an integrated surveillance protocol. Ultimately, universal access to basic sanitation, clean water, and waste management should be provided, while respecting the needs and perceptions of local communities. ${ }^{38}$

Effective disease control and prevention strategies will also benefit from having more women and under-represented groups in higher ranking positions of power, decision making, or policy design. ${ }^{43}$ Women are traditionally responsible for care and work in the household and water collection and storage, which places them in closer contact with mosquito breeding sites and provides insight into effective interventions.

\section{Building capacity to confront novel pathogens}

Medical and public health staff need to be trained to tackle the complexity of disease transmission and the context in which it occurs. Specifically, five areas should be part of the curriculum:

- Recognition of arboviruses that pose a threat to public health, even if the current burden is low

- Data literacy, including an understanding of the importance of data collection and data analysis as the backbone of evidence based decision making

- Field based collaborative learning, ${ }^{44}$ or the unique opportunity to interact with local health staff, community members, policy makers, and government officials to discuss solutions for local problems

- Holistic view of health, or the understanding that disease transmission is often complex, and results from multiple layers of biological, genetic, medical, social, economic, ecological, and political factors

- The effects of climate change and climate variability on infectious disease.
While some countries have recommended the inclusion of social sciences in medical training, including Brazil, the breadth and depth of training remain uneven and needs better regulation. ${ }^{45}$ Skills in these five areas would facilitate local engagement, better surveillance and data analytics for policy making, and a more humanistic approach to public health.

Enforcing environmental and indigenous community protection regulations may help mitigate forest disturbances, but it is unlikely that environmental change caused by development projects and deforestation will cease altogether in the near future. When considering the impacts of deforestation and climate change on the Amazon rainforest, and when planning for mitigation and regional and global solutions, it is imperative to consider effects, including unintended ones, on traditional ways of life. ${ }^{46}$

Interventions should be designed to respect local community needs, and perceptions and community engagement should be central to preparedness of protocols for the control of vectorborne diseases. Integrated surveillance protocols that track the circulation of pathogens and detect climate anomalies and early stages of disease outbreaks in all countries comprising the Amazon rainforest, are critical to prevent future spillover and explosive epidemics in one of the world's most vulnerable climate change hotspots.

Published maps are provided without any warranty of any kind, either express or implied. BMJ remains neutral with regard to jurisdictional claims in published maps.

We thank the National Socio-Environmental Synthesis Center (SESYNC) for providing the intellectual environment and collaboration between the authors that gave rise to this writing. RL is supported by a Royal Society Dorothy Hodgkin Fellowship and SL by a Royal Society Research Grant for Research Fellows. RML is supported by PDJ INOVA/Fiocruz fellowship.

Competing interests: We have read and understood BMJ policy on declaration of interests and have no relevant interests to declare.

Provenance and peer review: Commissioned; externally peer reviewed.

This article is part of a series commissioned by The $B M J$ for the World Innovation Summit for Health (WISH) 2020. The BM/ peer reviewed, edited, and made the decisions to publish. The series, including open access fees, is funded by WISH.

Rachel Lowe, associate professor and Royal Society Dorothy Hodgkin fellow ${ }^{1,2,3}$

Sophie Lee, doctoral student ${ }^{1,2}$

Raquel Martins Lana, postdoctoral scientist ${ }^{4}$

Cláudia Torres Codeço, Researcher ${ }^{4}$

Marcia C Castro, Professor $^{5}$

Mercedes Pascual, Professor ${ }^{6}$
${ }^{1}$ Centre on Climate Change and Planetary Health, London School of Hygiene and Tropical Medicine, London, UK

${ }^{2}$ Centre for Mathematical Modelling of Infectious Diseases, London School of Hygiene and Tropical Medicine, London, UK

33arcelona Institute for Global Health (ISGlobal), Barcelona, Spain

${ }^{4}$ Programa de Computação Científica, Fundação Oswaldo Cruz, Rio de Janeiro, Brazil

${ }^{5}$ Department of Global Health and Population, Harvard T H Chan School of Public Health, Boston, Massachusetts, USA

${ }^{6}$ Department of Ecology and Evolution, University of Chicago, Chicago, Illinois, USA

Correspondence to: M Pascual pascualmm@uchicago.edu

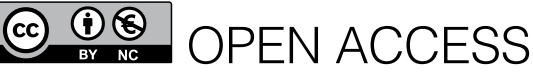

This is an Open Access article distributed in accordance with the Creative Commons Attribution Non Commercial (CC BY-NC 4.0) license, which permits others to distribute, remix, adapt, build upon this work non-commercially, and license their derivative works on different terms, provided the original work is properly cited and the use is non-commercial. See: http://creativecommons.org/ licenses/by-nc/4.0/.

\section{D) Check for updates}

1 Castro MC, Baeza A, Codeço CT, et al. Development, environmental degradation, and disease spread in the Brazilian Amazon. PLoS Biol 2019;17:e3000526. doi:10.1371/journal. pbio.3000526

2 Messina JP, Brady OJ, Golding N, et al. The current and future global distribution and population at risk of dengue. Nat Microbiol 2019;4:1508-15. doi:10.1038/s41564-019-0476-8

3 Musso D, Cao-Lormeau VM, Gubler DJ. Zika virus: following the path of dengue and chikungunya?Lancet 2015;386:243-4. doi:10.1016/ S0140-6736(15)61273-9

4 Yactayo S, Staples JE, Millot V, Cibrelus L, RamonPardo P. Epidemiology of Chikungunya in the Americas. J Infect Dis 2016;214(suppl 5):S441-5. doi:10.1093/infdis/jiw390

5 Lowe R, Barcellos C, Brasil P, et al. The Zika virus epidemic in Brazil: from discovery to future implications. Int J Environ Res Public Health 2018;15:96. doi:10.3390/ijerph15010096

6 Pan American Health Organization / World Health Organization. Epidemiological Update: Dengue. 7 February 2020. https://www.paho.org/en/ documents/epidemiological-update-dengue-7february-2020

7 Lowe R, Bailey TC, Stephenson DB, et al. The development of an early warning system for climate-sensitive disease risk with a focus on dengue epidemics in Southeast Brazil. Stat Med 2013;32:864-83. doi:10.1002/sim.5549

8 Floss M, Barros E. Lancet Countdown 2018 report: briefing for Brazilian policymakers. 2018. https://storage.googleapis.com/lancetcountdown/2019/10/2018-lancet-countdownpolicy-brief-brazil.pdf.

9 Barcellos C, Lowe R. Expansion of the dengue transmission area in Brazil: the role of climate and cities. Trop Med Int Health 2014;19:159-68 doi:10.1111/tmi.12227

10 Guagliardo SA, Barboza JL, Morrison AC, Astete H, Vazquez-Prokopec G, Kitron U. Patterns of geographic expansion of Aedes aegypti in the Peruvian Amazon. 
PLoS Negl Trop Dis 2014:8:e3033. doi:10.1371/ journal.pntd.0003033

11 Ríos-Velásquez CM, Codeço CT, Honório NA, et al. Distribution of dengue vectors in neighborhoods with different urbanization types of Manaus, state of Amazonas, Brazil. Mem Inst Oswaldo Cruz 2007;102:617-23. doi:10.1590/S007402762007005000076

12 Getis A, Morrison AC, Gray K, Scott TW. Characteristics of the spatial pattern of the dengue vector, Aedes aegypti, in Iquitos, Peru. Am / Trop Med Hyg 2003;69:494-505. doi:10.4269/ ajtmh.2003.69.494

13 Becker BK. Undoing the myths: the Amazon-an urbanized forest. In: Brazilian perspectives on sustainable development of the Amazon region. Vol 15. CRC Press, 1995: 53

14 Dal'Asta AP, Lana RM, Amaral S, Codeço CT, Monteiro AMV. The urban gradient in malaria-endemic municipalities in Acre: revisiting the role of locality. Int J Environ Res Public Health 2018;15:1254. doi:10.3390/ijerph15061254

15 Ministério da Saúde. Dengue-Situação epidemiológica/Dados. 2020.https://antigo. saude.gov.br/saude-de-a-z/dengue/situacaoepidemiologica-dados

16 Coelho FC, Lana RM, Cruz OG, et al. Assessing the potential impact of COVID-19 in Brazil: mobility, morbidity and the burden on the health care system. Health Care Syst 2020;•••:3222020. doi:10.2139/ ssrn.3559609

17 Vasconcelos PF, Calisher CH. Emergence of human arboviral diseases in the Americas, 2000-2016. Vector Borne Zoonotic Dis 2016;16:295-301. doi:10.1089/vbz.2016.1952

18 Dégallier N, Travassos da Rosa A, Vasconcelos PF, et al. Modifications of arbovirus transmission in relation to construction of dams in Brazilian Amazonia. Cienc Cult 1992;44:124-35.

19 Vasconcelos PF, Travassos da Rosa AP, Rodrigues SG, Travassos da Rosa ES, Dégallier N, Travassos da Rosa JF. Inadequate management of natural ecosystem in the Brazilian Amazon region results in the emergence and reemergence of arboviruses. Cad Saude Publica 2001;17(Suppl):155-64. doi:10.1590/ S0102-311X2001000700025

20 Ellwanger JH, Kulmann-Leal B, Kaminski VL, et al. Beyond diversity loss and climate change: Impacts of Amazon deforestation on infectious diseases and public health. An Acad Bras Ciênc 2020;92.

21 Grillet ME, Moreno JE, Hernandez JV, et al. Malaria in southern Venezuela: the hottest hotspot in Latin America.bioRxiv 2020 doi:10.1101/2020.03.13.990457

22 Souza PF, Xavier DR, Suarez Mutis MC, et al. Spatial spread of malaria and economic frontier expansion in the Brazilian Amazon. PLoS One 2019;14:e0217615. doi:10.1371/journal. pone. 0217615

23 Lana RM, Gomes MFDC, Lima TFM, Honório NA Codeço CT. The introduction of dengue follows transportation infrastructure changes in the state of
Acre, Brazil: A network-based analysis. PLoS Negl Trop Dis 2017;11:e0006070. doi:10.1371/journal. pntd.0006070

24 Marengo JA, Espinoza JC. Extreme seasonal droughts and floods in Amazonia: causes, trends and impacts. Int J Climatol 2016;36:1033-50. doi:10.1002 joc. 4420

25 Cai W, Borlace S, Lengaigne M, et al. Increasing frequency of extreme El Niño events due to greenhouse warming. Nat Clim Chang 2014;4:111 6. doi:10.1038/nclimate2100.

26 Fonseca MG, Anderson LO, Arai E, et al. Climatic and anthropogenic drivers of northern Amazon fires during the 2015-2016 El Niño event. Ecol Appl 2017;27:2514-27. doi:10.1002/eap.1628

27 Moura MM, Dos Santos AR, Pezzopane JEM, et al. Relation of El Niño and La Niña phenomena to precipitation, evapotranspiration and temperature in the Amazon basin. Sci Total Environ 2019;651:1639-51. doi:10.1016/i. scitotenv.2018.09.242

28 Wang B, Luo X, Yang Y-M, et al. Historical change of El Niño properties sheds light on future changes of extreme El Niño. Proc Natl Acad Sci U SA 2019;116:22512-7. doi:10.1073/ pnas.1911130116

29 Lim EP, Hendon HH, Hope P, Chung C, Delage F, McPhaden MJ. Continuation of tropical Pacific Ocean temperature trend may weaken extreme El Niño and its linkage to the Southern Annular Mode. Sci Rep 2019;9:17044. doi:10.1038/s41598-01953371-3

30 Jiménez-Muñoz IC, Mattar C, Barichivich J, et al. Record-breaking warming and extreme drought in the Amazon rainforest during the course of El Niño 2015-2016. Sci Rep 2016;6:33130. doi:10.1038/ srep33130

31 WWF Climate Change Programme. Climate change impacts in the Amazon: review of scientific literature. 2006. https://wwf.panda.org/wwf news/?64240\%2FClimate-Change-Impacts-in-theAmazon-Review-of-scientific-literature

32 Marengo JA, Souza CMJr, Thonicke K, et al. Changes in climate and land use over the Amazon region: current and future variability and trends. Front Earth Sci 2018;6:228. doi:10.3389/feart.2018.00228

33 Nobre CA, Sampaio G, Borma LS, Castilla-Rubio JC, Silva JS, Cardoso M. Land-use and climate change risks in the Amazon and the need of a nove sustainable development paradigm. Proc Natl Acad Sci U S A 2016;113:10759-68. doi:10.1073/ pnas.1605516113

34 Lowe R, Gasparrini A, Van Meerbeeck C), et al. Nonlinear and delayed impacts of climate on dengue risk in Barbados: A modelling study. PLoS Med 2018;15:e1002613. doi:10.1371/journal. pmed.1002613

35 Mordecai EA, Cohen JM, Evans MV, et al. Detecting the impact of temperature on transmission of Zika, dengue, and chikungunya using mechanistic models. PLoS Negl Trop Dis 2017;11:e0005568. doi:10.1371/journal.pntd.0005568
36 Huber JH, Childs ML, Caldwell IM, Mordecai EA. Seasonal temperature variation influences climate suitability for dengue, chikungunya, and Zika transmission. PLoS Negl Trop Dis 2018;12:e0006451. doi:10.1371/journal. pntd.0006451

37 Vincenti-Gonzalez MF, Tami A, Lizarazo EF, Grillet ME. ENSO-driven climate variability promotes periodic major outbreaks of dengue in Venezuela. Sci Rep 2018;8:5727. doi:10.1038/s41598-01824003-z

38 Giatti LL, Cutolo SA. Acesso à água para consumo humano e aspectos de saúde pública na Amazônia Legal. Ambiente Soc 2012;15:93-109. doi:10.1590/ S1414-753X2012000100007

39 InfoDengue. a nowcasting system for the surveillance of dengue fever transmission |bioRxiv 2020 [Preprint.] http://biorxiv.org/content/ early/2016/03/29/046193

40 Lowe R, Barcellos C, Coelho CA, et al. Dengue outlook for the World Cup in Brazil: an early warning model framework driven by real-time seasonal climate forecasts. Lancet Infect Dis 2014;14:619-26. doi:10.1016/S1473-3099(14)70781-9

41 Lowe R, Stewart-Ibarra AM, Petrova D, et al. Climate services for health: predicting the evolution of the 2016 dengue season in Machala, Ecuador. Lancet Planet Health 2017;1:e142-51. doi:10.1016/ S2542-5196(17)30064-5

42 Monteiro WM, Barbosa MDGV, Guerra JAO, et al. Driving forces for strengthening the surveillance of Chagas disease in the Brazilian Amazon by "training the eyes" of malaria microscopists. Rev Soc Bras Med Trop 2020;53:e20190423. doi:10.1590/00378682-0423-2019

43 Wenham C, Nunes J, Correa Matta G, de Oliveira Nogueira C, Aparecida Valente P, Pimenta DN. Gender mainstreaming as a pathway for sustainable arbovirus control in Latin America. PLoS Negl Trop Dis 2020;14:e0007954. doi:10.1371/journal. pntd.0007954

44 Wilson ME, Fregni F, de S M Veras MA, et al. Collaborative teaching and learning: a model for building capacity and partnerships to address NTDs. PLoS Negl Trop Dis 2011;5:e939. doi:10.1371/ journal.pntd.0000939

45 Nunes ED, Hennington EA, de Barros NF, et al. The teaching of social sciences in medical schools: revision of experiences. Cien Saude Colet 2003;8:209-25. doi:10.1590/S141381232003000100015

46 World Rainforest Movement. Brazil: voices of local communities in Acre denounce violations in Community-based Sustainable Forest Management. 2013.https://wrm.org.uy/articles-from-the-wrmbulletin/section1/brazil-voices-of-localcommunitiesin-acre-denounce-violations-in-community-basedsustainable-forestmanagement/

Cite this as: $B M / 2020 ; 371: \mathrm{m} 4385$

http://dx.doi.org/10.1136/bmj.m4385 